Erratum

\title{
Erratum: Wu, C.; Shen, H.; Wang, K.; Shen, A.; Deng, J. and Gan, M. Landsat Imagery-Based Above Ground Biomass Estimation and Change Investigation Related to Human Activities. Sustainability 2016, 8, 159
}

\section{Sustainability Editorial Office}

MDPI AG, CH-4057 Basel, Switzerland; Tel.: +41-61-683-7735

Received: 9 May 2016; Accepted: 9 May 2016; Published: 12 May 2016

In the published paper [1], Figures 5 and 6 were inadvertently exchanged in the PDF file. The correct Figures are as follows:

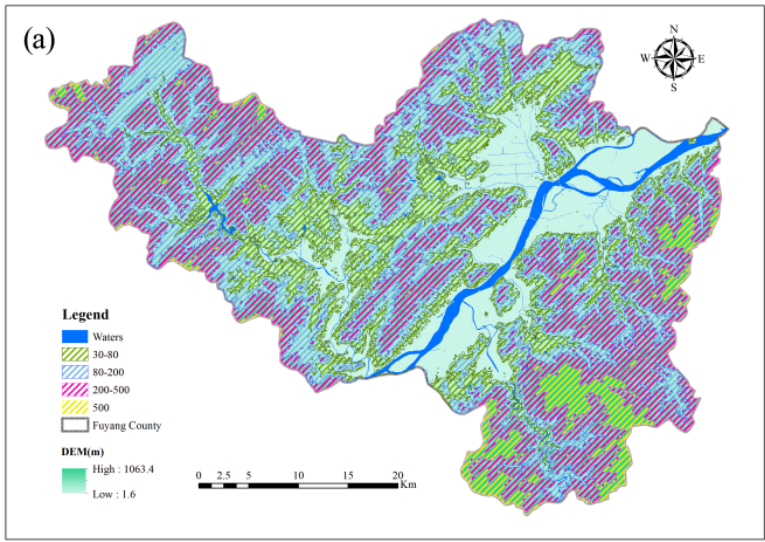

(b)

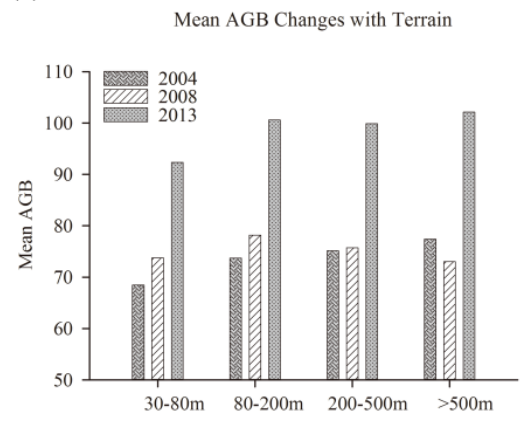

Figure 5. (a) Map of elevation stratification, and (b) change of AGB with stratified terrain.

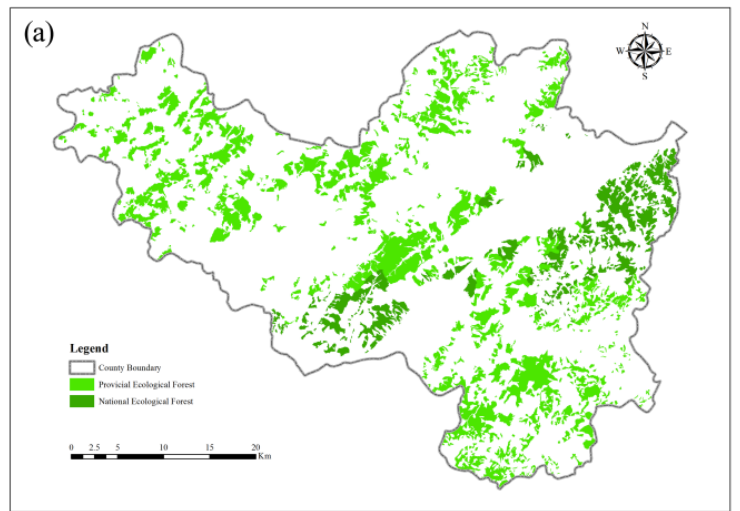

(b)

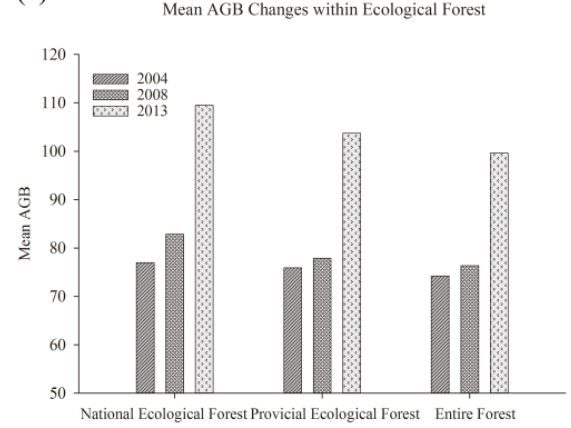

Figure 6. (a) Map of two-level ecological forest, and (b) change of AGB within ecological forest.

We apologize for any inconvenience caused to the readers by these changes. The manuscript will be updated and the original will remain available from the article webpage. 


\section{Reference}

1. Wu, C.; Shen, H.; Wang, K.; Shen, A.; Deng, J.; Gan, M. Landsat Imagery-Based Above Ground Biomass Estimation and Change Investigation Related to Human Activities. Sustainability 2016, 8, 159. [CrossRef]

(C)

(C) 2016 by the author; licensee MDPI, Basel, Switzerland. This article is an open access article distributed under the terms and conditions of the Creative Commons Attribution (CC-BY) license (http://creativecommons.org/licenses/by/4.0/). 